\title{
Language and Conflict: Arguing for Interdisciplinarity and Usefulness
}

\author{
Karol Janicki
}

Part I-General considerations

"Not everything that counts can be counted"

(Collini 2012, 120)

\section{Some remarks on interdisciplinarity and the humanities}

This essay includes two parts. In the first, I briefly highlight the value of interdisciplinary research and its usefulness to society at large. I draw upon philosophy (the philosophy of language, in particular) to indicate that it is possible to argue for any study to be socially relevant, difficult as it may be to argue for some studies to be so. In the second part, I indicate that my own recent research can be seen as interdisciplinary and useful outside academia.

There has recently been much discussion, both formal and informal, about the relevance of the humanities as an academic field to society outside of the academia. This discussion has included references to interdisciplinary research and its possible benefits. With reference to interdisciplinarity, opinions have been voiced on how the social/human sciences relate to the natural ones, and how the one can contribute to the development of the other. As expected, while pondering the question of the relevance of the humanities to the larger non-academic community, there have been critics, advocates, sticklers, enthusiasts, doubt mongers, fear mongers, and others. Needless to say, the question of what we humanists 
do and how useful to the society we are has been addressed within the academia itself and especially in political circles, in Norway and in other countries.

Some critics are of the opinion (mainly in private and semi-private conversations) that what we, the humanists, are concerned with in our teaching, research and publications is hardly useful and widely irrelevant to what the society at large needs. In public statements, this opinion is usually toned down or labeled as untrue. However, the recent perceived or real financial cuts that some humanities departments have suffered from, leave little doubt that the humanities are not valued highly by those who control university funding. Quite often, the natural sciences, and the technologies emerging from them or related to them, are praised as advancing society. This may be well deserved, although what it means to "move society forward" remains questionable (see the discussion of "useful" and "relevant" below). Extolling the virtues of the natural sciences and the technologies associated with them should not, however, lead to a denigration of the humanities. Many authors have recently discussed the role of the humanities in contemporary society, and some have argued that the humanities should not be looked down upon, as they often are, but rather fully acknowledged and promoted (see, for instance, Kronman 2008, Nussbaum 2012, Small 2013, Berg \& Seeber 2016). Research related to both the natural sciences and the humanities may, in fact, be seen as supplementing each other. In sum, and also metaphorically, it would probably be difficult to live only with a computer and without a book on human behavior. We might actually be happier with only a book on human behavior and without a computer, rather than the other way round. Let us assume, however, that we need both.

One of the reasons why we may assume that we need both is the value of interdisciplinary thinking. The humanities may be viewed as a set of disciplines (or as a single large discipline if one wishes to see the humanities as such). If one appreciates the value of interdisciplinary thinking, one should be tempted to perceive the humanities as a fragment of academic or scientific activity that has potential benefits, including tangible social ones. The richness of one discipline (whether we see it as belonging to the humanities, to the natural sciences, to technology, to the arts, etc.) may feed another, no matter how distant the goals and research methods of the two interacting disciplines are from each other. Unexpected 
connections that our brain makes between different ideas, issues, facts, etc. (how it connects the dots, using psychological terminology; see for instance, Shermer 2011) may serve different purposes. One of them is to formulate new research questions, viewed as interdisciplinary or not. In other words, attention to the natural sciences and technological developments can lead to new ideas in the humanities, and attention to how human beings behave under everyday conditions - what we expect, what we feel, how we suffer-may lead to new research in the natural sciences and to new technological developments.

The issue of suffering brings me to one specific example of the interaction and interpenetration that may occur among various kinds of ideas, observations, emotions, etc. Alfred Korzybski, the Polish-American engineer who founded what is known as general semantics, is reported to have commented on the horrors of World War I: "He was appalled by the massive war destruction and determined to answer the question of how humans so successfully advance technologically yet make such a mess of their general human affairs" (Kodish \& Kodish 2001, 17). Very likely, the sight of the bodies lying around in the streets, of the injured, and of the dying made an overwhelming impression on him. He may have asked himself questions such as how can we, as humans, be smart enough to build impressive bridges, airplanes, and automobiles, and not sensible enough to prevent wars and the usual carnage and suffering that accompany them. This led Korzybski to later conclude that our lack of awareness of how language works and of how we create meaning may be one of the reasons why we tend to engage in conflicts, wars, and atrocities of all kinds. This thought, in turn, led him to found a new discipline-general semantics - which, by any definition, is better placed in the humanities than in the natural sciences or in the area of technology (see Korzybski 1933). Thus, an engineer's observation of how humans behave led to an insight that supported a whole new discipline. Bod (2013) reports a number of cases where ideas and stimulations that emerge in what is commonly seen as one discipline have permeated another. He points out that, throughout history, ideas within the humanities have given rise to ideas and developments in the natural sciences and technologies. Bod stresses that scientists such as Galileo, Kepler and Newton were also philologists $(2013,353)$. 
While the above-mentioned Korzybski example may be best seen as illustrating interdisciplinary thinking, examples of how researchers across disciplines actually cooperate and arrive at new hybrid disciplines, are easy to find. Recent developments in linguistics provide numerous examples of how the field has been successfully combined with disciplines such as law, medicine and education (see, for instance, Coulthard \& Johnson 2007), which in turn leads to new perspectives on how the legal process is to be viewed or on how doctor-patient interaction can be improved-clearly findings of interest to society at large. Consider Philips (1998), for example, who shows how judges differ with reference to the kinds of questions they ask ("yes or no questions," or open questions) and how different types of questions may influence the legal proceedings and the final sentence. Examples such as this seem to be rewarding, powerful, and encouraging enough to allow us to view academia as one realm of activity rather than a set of separate compartments, the largest of these being the natural sciences and the social sciences/humanities. Separate compartments (usually called departments) may be handy if one is to hold meetings, pick up mail or deliver reports, but they appear much less advantageous when it comes to developing new ideas and embarking on new projects.

\section{What is useful or socially relevant research?}

Recently, at many universities and other academic institutions, researchers have been strongly encouraged to cooperate across disciplines. This has been manifested, for example, in the funds allotted to large international and interdisciplinary projects (in which at least three institutions are involved), rather than to low profile individual ones. I assume that the tacit assumption behind this big-project thinking has been that such projects are probably more useful and socially beneficial both in the short and in the long term. This brings us directly to the title question of this section.

The discussions of and disagreements about how useful/useless or socially relevant a study is may be taken up as a linguistic or philosophical question. In other words, we may address principally the questions what does "useful" mean? and what does "socially relevant" mean? These are what some researchers call what-is-questions (Popper 1972), and others what-is-irritants. There are still many thinkers and researchers who be- 
lieve that there is some essence in "usefulness" and "social relevance"; this position is often referred to as essentialism (Hallett 1991). If one adopts a version of essentialist philosophy, one will be tempted to believe that, once the essence of "usefulness" is located, a study may be judged to be "useful" or "useless," "socially relevant," or "socially irrelevant," in some absolute sense. Essentialism promotes binary opposition ("yes" or "no" answers on any question) and, in my view, does not help us to understand how the world works.

I have argued for a non-essentialist position on several occasions (see, for instance, Janicki 2006, 2010b) and I fully endorse it in connection with the discussion of what kind of research may be seen as useful or socially relevant. Here, I wish to invoke two arguments supporting my non-essentialist reasoning. One is extremely simple, and is obvious to any linguist, namely, that "useful" and "socially relevant" are words and only words, which, like all words (except onomatopoeic ones) refer to some other things in a conventional and arbitrary way. In other words, "useful" means what we, language users, agree it to mean. We may disagree, argue, or be furious about how some people use the word, but, ultimately, the word will always mean what it means to a group of people or to an individual. Non-essentialism involves the position that meaning is in the individual language user's mind rather than in the word, in some absolute sense.

Another (related) non-essentialist argument as to what "useful research" means takes us to the realm of experience. Meanings of words, which call up concepts and mental images, are grounded in our experience (on the question of meaning and experience, see, for instance, Lakoff 1987, Gibbs 1999, Evans \& Green 2006). To put it differently, what the words "useful research" mean to me depends upon the experience that I have had throughout my lifetime with the words "useful and research." What the words "useful research" mean to you, the reader of this essay, depends upon the experience that you have had throughout your lifetime with the words "useful and research." No exo-experiential and exo-human meaning of "useful research" exists! Needless to say, people are all different, as are their experiences in relation to the words "useful research." To put it in very simple terms, we have different ideas of what is useful research, no matter how similar to other people in this respect we may turn out to be. We understand and share the meaning of "useful 
research" with other people to the extent that we share with them the experience in which the words we use are grounded.

One of the consequences of non-essentialist philosophy is that concepts can be best viewed as continua. Like most other concepts, the crucial ones discussed in this essay_ - "useful" and "socially relevant"-may then be treated as continua as well. In other words, rather than saying that a study, or a discipline, is useful to something or not, we should be prepared to say that it may be more useful, less useful, very useful, almost useless, etc. This approach allows us to make non-categorical evaluations (e.g., linguistics is quite useful for some people in some situations), which are so much easier to make than categorical ones (e.g., linguistics is definitely useful). Viewing "usefulness" or "social relevance" as continua allows us to point to typical cases, about which we will tend to agree. For instance, given the finding that the way questions from the prosecution are asked in court may affect the way they are answered by the defendant, we will tend to agree, I think, that such findings may have significant legal consequences. Research on how such questions and answers work is then very likely to be widely seen as socially useful. We will, however, tend to disagree or be in doubt about borderline cases, for example, about whether research on accommodation in discourse (i.e., on how we adapt our language to the language of our interlocutors) is socially useful. Some of us will probably see it as useful; others as hardly useful or as useless.

The above brief argument against essentialist thinking does not directly involve the question of interdisciplinary research, but the former should not be seen as totally unrelated to the latter. On the contrary, the question of what is or is not useful may be more pressing in view of the current almost ubiquitous administrative encouragement to develop interdisciplinary projects. As stressed at the beginning of this section, we may assume that one of the main reasons interdisciplinary projects are encouraged and funded generously is that the benefactors see them as useful. However, as the argument against essentialism shows, whether one type of research or a particular research project is useful or relevant to society at large can always be called into question. This is independent of whether we are engaged in one discipline or in multi-disciplinary research, whatever the definition of a discipline. 


\section{Part II-my own research}

The considerations in Part I should lead us to the conclusion that it is up to the individual, or a group of individuals, to decide whether a particular study, or research project, or a discipline, is useful or relevant to society at large, and to what extent. No one answer to questions of relevance and usefulness should be expected. Since any dots (ideas, views, beliefs, etc.) can be connected, and since we as individuals are free to make different connections, it is possible to argue that any research in the humanities is useful and relevant, at least to some extent or potentially in the long run. I do not see my own research as an exception; I consider it to be useful and relevant. It is, however, ultimately up to the individual reader to share my opinion or disagree with me.

My own research may be considered interdisciplinary, as it combines linguistics, communication, psychology, sociology, politics, etc. Although the considerations in Part I above encourage interdisciplinarity, the usefulness of my research, as I see it, is not due to the interdisciplinary approach that I adopt. I consider its usefulness to be related to what I believe people need to know; I can only hope that many other people will agree with me. However, to be faithful to the non-essentialist philosophy that I advocate and live by, I am prepared to accept the opinion that my research is completely or partly useless, should anybody want to see it as such. No research is useful in its own right; it is ultimately up to a group or an individual to evaluate it as such.

In recent years, my research has focused on two main topics: (1) language and conflict, and (2) lay views of language (folk linguistics). On the first topic, I have published four books: Janicki 1999, 2006, 2010b, and 2015. In these books, I show how our views of language can lead to peace building, neutrality and indifference, or to destruction, conflict building, and warmongering. The philosophical basis for my reasoning is non-essentialism (see above), which implies a philosophical stance on meaning. To reiterate, this stance involves the assumption that words do not have basically one correct and ultimate meaning. The non-essentialism that I promote involves the assumption that language users assign meaning to words, and that the assigned meaning differs depending on who the language user is, their education, profession, sex, past experiences, etc.

A related idea permeating my research is that essentialist views of meaning lead to conflict. Analyses of numerous cases of conflicts (e.g., 
political) support the idea that in conflict situations much depends on how the people involved handle language. Moreover, there is overwhelming support for the view that the belief that there is one correct meaning of a word is socially dangerous. It leads to continuous disagreements as to what words mean, should mean, or have meant. Fighting about word meanings easily leads to verbal squabbles going beyond language issues, and may ultimately lead to physical violence.

With regard to the second topic-lay views of language (folk linguistics) - my research has addressed the question of what the lay language user perceives as language-related problems and how they feel such problems could be solved. This research has been concerned with what I see as one of the basic questions of language and communication. I assume that linguists may be considered useful by lay language users if the latter feel they need a linguist to solve language-ridden problems (on this point, see also Roberts 2003). Identifying the problems in question may help the linguist to direct his or her research toward what the lay language user really cares about.

My research on lay people's views on language-ridden problems (published mainly in Janicki 2002, 2010a, 2011, and 2014) has shown that the major problems are related to meaning, misunderstanding, miscommunication, and related phenomena. In other words, lay language users report that they face problems and difficulties, or undergo stress, when they do not understand other people (e.g., doctors, lawyers, but also, importantly, colleagues, friends, or family members), when they misunderstand other people, or when they feel they are misunderstood or not understood. Although respondents report on other language-related problems (for instance, the inability to express verbally what one wants to say), in my view, meaning and understanding related problems become most salient and most socially relevant.

Meaning, understanding and misunderstanding issues appear to bind my research on language and conflict on the one hand, and that on lay views of language problems on the other. Given that language permeates most of our daily activities, and given that talking to other people, understanding them, and trying to make ourselves understood occupies a significant part of our daily lives, the social relevance of research on language, conflict and understanding can be easily argued for, no matter 
how unusual and far from the typical our definition of "social relevance" might be.

\section{Conclusion}

In this essay, I set out to do three things: (1) to highlight the value of interdisciplinary thinking and research activities (including interaction between the humanities and the natural sciences/technology); (2) to show that the question of what is useful or socially relevant research may be tackled as a philosophical issue and is a matter of contention; and (3) to draw upon my own recent research as an example of what I personally consider to be useful research, while leaving it entirely up to others to agree or disagree with me. My rationale for labeling my own research as useful springs from the assumption that, given the omnipresence of conflict in human affairs, it would be useful to have the necessary skills to understand and handle it. My main claim is that, given the central place of language in conflict, our knowledge about how language works can contribute to averting it. Furthermore, I claim that, in order to avoid conflict, it is beneficial to adopt a non-essentialist philosophical position.

What is important to people, what we care about, how we reason, what we expect, how we thrive or suffer is all studied by and reflected on by the scholars and scientists in a myriad of disciplines and in projects that can be seen as crossing the discipline boundaries of history, sociology, cognitive psychology, art, philosophy, economy, and others. Given the pervasiveness of language in practically all walks of life, linguistics may be seen as a valuable contributor to such projects.

\section{References}

Berg, Maggie, and Barbara Seeber. 2016. The Slow Professor: Challenging the Culture of Speed in the Academy. Toronto: University of Toronto Press.

Bod, Rens. 2013. A New History of the Humanities: The Search for Principles and Patterns from Antiquity to the Present. Oxford: Oxford University Press.

Collini, Stefan. 2012. What are Universities for? London: Penguin.

Coulthard, Malcolm, and Alison Johnson. 2007. An Introduction to Forensic Linguistics: Language in Evidence. New York: Routledge. 
Evans, Vyvyan, and Melanie Green. 2006. Cognitive Linguistics: An Introduction. Edinburgh: Edinburgh University Press.

Gibbs, Raymond W. Jr. 1999. Intentions in the Experience of Meaning. Cambridge: Cambridge University Press.

Hallett, Garth L. 1991. Essentialism: A Wittgensteinian Critique. Albany: State University of New York Press.

Janicki, Karol. 1999. Against Essentialism: Toward Language Awareness. Munich: Lincom Europa.

Janicki, Karol. 2002. "A Hindrance to Communication: The Use of Difficult and Incomprehensible Language." International Journal of Applied Linguistics 12 (2):194-217.

Janicki, Karol. 20 o6. Language Misconceived: Arguing for Applied Cognitive Sociolinguistics. London: Routledge.

Janicki, Karol. 2010a. "Lay People's Language Problems." International Journal of Applied Linguistics 20 (1):73-94.

Janicki, Karol. 201ob. Confusing Discourse. Basingstoke: Palgrave Macmillan.

Janicki, Karol. 2011. "Communication and Understanding." In Applied Folk Linguistics (AILA Review 24), edited by Antje Wilton and Martin Stegu, 68-77. Amsterdam: John Benjamins.

Janicki, Karol. 2014. "Connecting the Linguist to Industry and Public Institutions." International Journal of Applied Linguistics 24 (1):38-49.

Janicki, Karol. 2015. Language and Conflict. London: Palgrave Macmillan. Kodish, Susan Presby, and Bruce I. Kodish. 2001. Drive Yourself Sane: Using the Uncommon Sense of General Semantics. Pasadena, CA.: Extensional Publishers.

Korzybski, Alfred. 1933. Science and Sanity: An Introduction to Non-Aristotelian Systems and General Semantics. Clinton, MA.: Colonial Press. Kronman, Anthony. 2008. Education's End: Why our Colleges and Universities Have Given up on the Meaning of Life. New Haven: Yale University Press.

Lakoff, George. 1987. Women, Fire and Dangerous Things. Chicago: The University of Chicago Press.

Nussbaum, Martha. 2012. Not for Profit: Why Democracy Needs the Humanities. Princeton: Princeton University Press. 
Phillips, Susan U. 1998. Ideology in the Language of Judges: How Judges Practice Law, Politics, and Courtroom Control. Oxford: Oxford University Press.

Popper, Karl. 1972. Objective Knowledge: An Evolutionary Approach. Oxford: Clarendon.

Roberts, Celia. 2003. "Applied Linguistics Applied". In Applied Linguistics and Communities of Practice, edited by Srikant Sarangi and Theo van Leeuwen, 132-49. (British Studies in Applied Linguistics). London: Continuum.

Shermer, Michael. 2011. The Believing Brain: From Spiritual Faiths to Political Convictions. How to Construct Beliefs and Reinforce them as Truths. London: Constable and Robinson Ltd.

Small, Helen H. 2013. The Value of the Humanities. Oxford: Oxford University Press. 
